\title{
Specific anosmia in humans and animals: Environmental and genetic influences
}

\author{
M.A. Klyuchnikova, V.V. Voznessenskaya \\ A.N. Severtsov Institute of Ecology and Evolution, 119071, Leninski pr., 33, Moscow, Russia. \\ E-mail: klyuchnikova@gmail.com
}

Received: 15.06.2019. Accepted: 16.07.2019

\begin{abstract}
Olfaction plays a very important role across the lifespan of most mammalian species, including humans. Being the oldest, chemical communication is one of the least understood forms of communication due in part to the difficulty of detecting and measuring the chemicals in a sample. The ability to detect chemicals in the environment serves many functions. Individuals with specific anosmia, or "odor blindness", have significantly increased olfactory thresholds to particular odorants though they show normal general olfactory acuity. Hereby we review research on specific anosmia in humans, factors that may affect individual variation in olfaction as well as animal models of specific anosmia. Variability in sensitivity to odorants is influenced by genotype, age, gender, individual olfactory experience and environmental cues. Large data pile from human and animal studies suggests that not all factors are determined yet. The possibility of induction of olfactory sensitivity to biologically relevant chemical cues is discussed. Olfactory plasticity determines the adaptability of the species to the environment. Mechanisms that underlie the induction of sensitivity to the odorants still to be elucidated.
\end{abstract}

Keywords: Specific anosmia; chemical communication; olfactory receptors; environmental factors; androstenone; isovaleric acid

\section{Introduction}

Olfaction plays an important role across the lifespan of most mammalian species, including humans. Intra- and interspecific chemical communication is utilized for a variety of purposes. In many mammals such processes as foraging, reproduction, threat avoidance, social communication, raising offspring mainly rely on chemical cues. Behavioral and physiological responses to chemical cues influence spatial distribution and population interactions of the species.

Mammals are able to detect and discriminate a wide variety of odorants and chemical signals, such as pheromones. Humans, previously considered to be microsmatic, also proved to have excellent olfactory abilities (McGann, 2017). According to recent studies humans discriminate at least one trillion olfactory stimuli (Bushdid et al., 2014; Gerkin \& Castro, 2015). The impact of deficiency in sense of smell on health and well-being are commonly underestimated. Impairments in olfactory function significantly affect the quality of life and, oftentimes, overall health. Decreased sense of smell compromises the ability to detect the full array of food flavors and, thus, may lead to poor dietary choices resulting in nutrition-related health conditions such as malnutrition and obesity. Complete loss of the sense of smell even poses a safety concern because anosmic individuals are unable to detect warning odors such as gas leakage or the smell of the spoiled food. Anosmia and hyposmia, the inability or decreased ability to smell, affects about 3-20\% of the population, more commonly in elderly people (Boesveldt et al., 2017). Normally, the human olfactory abilities defined by means of olfactory thresholds to a number of substances vary between individuals. This variation reaches extreme values in case of specific anosmia, or "odor blindness" (Amoore, 1967). Specific anosmia is an inability to smell a particular odor while the majority of other odors are normally perceived. About ten specific anosmias to various groups of chemical compounds were described (Wysocki \& Beauchamp, 1991), though Croy et al. (2015) argued that their number is underestimated. Less is known about intraspecific variation in olfactory sensitivity among other mammalian species. Most of experimental data were obtained using laboratory mouse Mus musculus (Linnaeus, 1758) model. For instance, extreme variants of olfactory sensitivity corresponding to several types of specific anosmias in humans were described in laboratory mice (Wysocki et al., 1977; Price, 1977; Voznessenskaya et al., 1995). The phenomenon of specific anosmia attracts scientists' attention for many years because of its value for various studies to provide insight into fundamental basis of odor perception, olfactory loss, as well as inter- and intraspecies chemical communication. Main research in the area was focused on specific anosmias to odorants that could potentially play a role in the chemical communication of mammals, such as androstenone and isovaleric acid. Our review covers current research on specific 
anosmias occurring in humans; factors that may affect individual variation in olfaction; animal models of specific anosmia as well as underlying mechanisms of specific olfactory deficits. We pay special attention to the environmental influences. In our review, we aimed to place more than half a century research on specific anosmia in a framework of current knowledge about organization of olfactory reception, and to reveal existing gaps.

\section{Methodology for Review}

Here we review publications on specific anosmia and major principles of olfactory reception in human and animal species. Over $95 \%$ of publications we cite are indexed in PubMed, Web of Science or Scopus databases. A time period of publications is $1948-2019.85 \%$ of cited items are research papers, and $15 \%$ are relevant reviews.

\section{Historical perspective}

A term "specific anosmia" was introduced to a wide scientific audience in 1950-1970s by John E. Amoore (1930-1998). Much of the research in this field is still associated with his name. Amoore defined specific anosmia as "the condition in which a person of otherwise normal olfactory acuity cannot perceive a particular compound, at a concentration such that its odor is obvious to most other people" (Amoore, 1977). Amoore's interest in specific anosmia was interconnected with his stereochemical theory of olfaction and concept of primary odors. Amoore's theory of olfaction flowed out of Moncrieff's hypothesis that the olfactory system is composed of receptor cells of a few different types. Each represents a distinct "primary" odor, and odorous molecules produce their effects by fitting closely into "receptor sites" on these cells (Moncrieff, 1949). Amoore proposed that receptor cells are stimulated by different molecules depending on their size, shape or their charge (Amoore, 1952). Following ideas of Marcel Guillot (Guillot, 1948), he suggested that each type of specific anosmia corresponds to a genetic defect in the receptor cell that responds to one of classes of odorous substances. Amoore anticipated that, by analogy with color blindness, odor blindness would help to decipher olfactory code (Amoore, 1967). For the search of "primary odors" Amoore aimed to survey groups of related odorants in order to select the one with the largest threshold difference. Amoore and his colleagues conducted a preliminary survey of olfactory sensitivity to the supposed primary odorants using hundreds of people, and then groups of 10-30 subjects were selected as "normosmics" and "specific anosmics". In practice, the olfactory thresholds of specific anosmics should have exceeded the value of two standard deviations from the average value of the olfactory threshold in the population to a given substance. Thresholds were defined in a test where subjects had to choose two odorous bottles from a five bottle set. The ability to perceive a particular smell in subjects with specific anosmia was reduced by 10-1000 times compared to people with normal olfactory sensitivity. Amoore defined at least 8 types of primary odors (Amoore, 1979). Here we list these types with the corresponding primary odorants and percentage of anosmia occurrence: sweaty (isovaleric acid - 3\%), spermous (I-pyrroline - 16\%), fishy (trimethylamine $6 \%)$, malty (isobutyraldehyde - 36\%), urinous (5a-androst-16-en-3-one - 47\%), musky ( $\omega$-pentadecalactone - 12\%), minty (Icarvone - 8\%), camphor (1,8-cineole - 33\%). It should be noted that Amoore selected in the group of "specific anosmics" people with elevated thresholds to definite odors, but still not completely deprived of sensitivity to them, so it would be more correct to call them specific "hyposmics". People who are not sensitive even to the highest concentration (saturated vapors) of odorant were practically excluded from the Amoore's analysis. The percentage of such subjects in population, for example, in the case of specific anosmia to androstenone, may reach $50 \%$. Though the concept of "primary odors" is now largely forgotten, stereochemical theory of olfaction, in a broad sense, is widely accepted as it still accommodates the emerging data on olfactory reception processes (Hoehn et al., 2018).

Olfactory reception: Over the past two-three decades, a huge amount of data concerning molecular organization of odorant reception was acquired. In their most influential paper Nobel Prize winners Buck and Axel (1991) characterized rat olfactory receptor (OR) gene family. By their seven transmembrane domain structure and ability to interact with $G$ proteins, ORs were assigned to the superfamily of G protein-coupled receptors (GPCRs) (Kajiya et al., 2001; Krautwurst et al., 1998). Olfactory receptors are localized in the membrane of the cilia of the olfactory sensory neurons (OSNs), immersed in a layer of mucus. Apparently, odorant binding and activation of the OR occurs according to the known principles of ligand-receptor interaction. Experimentally, it was shown that several hydrophobic amino acid residues of the receptor protein are involved in the ligand binding and that transmembrane domains 3, 5 and 6 form a pocket for the binding of an odorant (Katada et al., 2005). A large repertoire of olfactory receptors is impressive. In mammals, OR genes comprise 3-5\% of the total number of genes, which makes the superfamily of OR genes one of the largest in the genome. Mouse genome contains about 1200 intact and potentially functional OR genes (Young \& Trask, 2002; Zhang \&Firestein, 2002), meanwhile in humans this number is lower and accounts for about 350 genes (Glusman et al., 2001; Zozulya et al., 2001). Total number of OR genes in the mammalian genome is even larger, as far as a significant part of Ors is represented by pseudogenes. For instance, in humans, about $50 \%$ of all Ors are pseudogenes; in mice and rats, the proportion of pseudogenes is smaller, about 20\%. It was noticed that the percentage of pseudogenes increases from rodents to monkeys and humans. It is speculated that reduction in the number of functional OR genes is accompanied by a decrease of species olfactory abilities (Touhara, 2008). Also some pseudogenes are considered "segregating", because of their segregation in populations between intact and pseudogene states. Analysis of several hundred human genomes showed that almost each individual set of olfactory receptor genes/pseudogenes differs from other, which, in turn, can be linked with variability in olfactory sensitivity (Menashe et al., 2003). 
Despite of the fact that the number of functional olfactory receptors is large, the number of smells that we can detect is incomparably greater, which leads to an idea of the combinatorial coding principle. More precisely, one receptor recognizes several odorants, and one odorant is detected by several receptors. According to the common hypothesis, referred as "one neuron - one receptor" hypothesis, only one type of olfactory receptor is expressed in one olfactory sensory neuron (OSN) in mammals (Mombaerts, 2004). Functional activation of a single OSN by several odorants was demonstrated quite a long time ago (Sicard \& Holley, 1984; Firestein et al., 1993; Sato et al., 1994). Due to application of advanced techniques, activation of OSNs expressing a certain type of olfactory receptor directly by a set of odorants was finally demonstrated (Zhao et al., 1998; Malnic et al., 1999, Abaffy et al., 2006). The conclusion that a combinatorial receptor code does exist at the peripheral level of olfactory system was based on the fact that there are many olfactory receptors with a unique spectrum of ligands, while each odorant is recognized by many types of receptors (Malnic et al., 1999; Touhara, 2002). John Amoore's and his predecessors' assumptions about receptor defects underlying specific anosmia, by analogy with color blindness, fit well into this modern concept of olfactory reception, genetic architecture of Ors and combinatorial receptor code. For instance, according to the combinatorial code principle, the fact that a specific anosmic detects a smell to a certain extent can be explained by the existence of several olfactory receptors for a given substance with varying degrees of affinity. One more class of chemosensory receptors in the main olfactory epithelium was described in 2006 (Liberles \& Buck, 2006). Trace amineassociated receptors (TAARs) also belong to $G$ protein-coupled receptors; several TAARs are definitely involved in detection of volatile amines (Liberles, 2015).

Variability in perception of androstenone and isovaleric acid odors: For more than half a century of research on specific anosmia, a large set of experimental data has been accumulated. One of the most important models of specific anosmia remained a specific olfactory deficit towards the boar sex pheromone androstenone (5a-androst-16-en-3-one, AND). Also significant amount of research was devoted to specific anosmia towards isovaleric acid (IVA). The most extensive study of human olfactory sensitivity up to nowadays ( 1.5 million respondents) was carried out in collaboration with the popular National Geographic magazine in 1986-1987. The study confirmed the prevalence of AND specific anosmia on different continents (35\% on average) (Gilbert \& Wysocki, 1987). Noteworthy, this study revealed that percentage of people unable to smell AND varied from region to region. Thus, olfactory sensitivity to AND differed in respondents of European origin residing in Africa vs. those residing in the UK. Such phenotypic variation suggests not only the involvement of genetic factors, but also some environmental influences. For instance, olfactory sensitivity to AND may be acquired after repeated exposures to the substance (details are provided in the subsequent sections of the review).

Researchers' attention was primarily attracted to specific anosmia to odorants that could potentially play a role in the chemical communication of mammals. Androstenone (AND) is a C19 steroid of gonadal origin abundant in boar saliva. AND is a sex pheromone in boar. In receptive female pigs, application of this substance facilitates the characteristic posture of lordosis (Reed et al, 1974). AND is found in human urine, blood plasma and axillary secretions; it is present in larger quantities in men than in women (Gower \& Ruparelia, 1993). Androstenone and structurally closely related steroid androstadienone were proposed as candidates for the role of modulatory human pheromones, but this statement remains speculative (Wyatt, 2015). However, the effects of AND on mood, sexual behavior and sexual attractiveness in humans were described (Cowley et al., 1977; Filsinger et al., 1984; Pause, 2004). Notably, Wyart et al. showed hormonal response in women to the presentation of the related steroid androstadienone. Smelling this compound maintained significantly higher levels of the hormone cortisol in saliva (Wyart et al., 2007). AND may also act as a chemical signal in the house mouse (M. musculus). AND presented in the context of the urine of a castrated male, induced aggressive reactions in SJL male mice towards scented intruders (Ingersoll \& Launay, 1986). We also demonstrated the involvement of an accessory olfactory system in the detection of androstenone in CBA inbred mouse strain, highly sensitive to this odor. Accessory, or vomeronasal, olfactory system is largely associated with the detection of pheromones in rodents. Using Fos-immunostaining, we observed neuronal activation in the receptor tissue of the mouse vomeronasal organ in response to stimulation with androstenone. Removal of the vomeronasal organ in CBA mice led to a significant decrease in sensitivity to androstenone (Voznessenskaya et al., 2010).

According to different estimates, from 30 to $50 \%$ of the human population has a specific anosmia to androstenone (Labows \& Wysocki, 1984; Gilbert \& Wysocki, 1987; Voznessenskaya \& Klyuchnikova, 2017). Lower estimates of the proportion of anosmics received in some studies (Bremner et al., 2003) may be explained by involvement in detection of another chemosensory structure, the trigeminal nerve system (Boyle et al., 2006). Notably, people highly sensitive to AND describe its smell as unpleasant, like urine and sweat. While low sensitive to AND people more often describe the smell as a pleasant, sweet and floral. On the side, the hedonic evaluation is a fairly stable characteristic of odorant (Yeshurun \& Sobel, 2010). At the same time, the higher the olfactory sensitivity to AND is, the more unpleasant this smell perceived. These variances in the qualitative characteristics of odor suggest the involvement of several types of olfactory receptors in the detection of androstenone.

Isovaleric acid (IVA) is the main component of the subauricular gland of the male pronghorn Antilocarpa americana (Ord, 1815), used for marking the territory (Muller-Shwarze et al., 1974). This compound was also found in the vaginal secretions of the rhesus monkey Macaca mulatta (Zimmermann, 1780) (Michael et al., 1971), in the vaginal (Michael et al., 1975) and sweat (Leyden et al., 1981) human secretions, in the urine and vaginal secretions of mice (Novikov, 1988). John Amoore estimated percentage of specific anosmia to IVA as 3\% (Amoore, 1977). In a later genetic study, scientists characterized another extreme variant of sensitivity to IVA - specific hyperosmia to this odorant (Menashe et al., 2007). The literature sources do not describe differences in the qualitative characterization of the odor of IVA in people with different olfactory thresholds, which indicate that different mechanisms underlie anosmia to the AND and IVA (for example, the different number of receptors involved in the perception of these two substances) (Amoore 1967, Menashe et al., 2007; Keller \& Vasshall, 2016). 
Interestingly, in addition to androstenone and isovaleric acid, a few other specific anosmias associated with human body odors were described, but they were less studied. For instance, Amoore characterized specific anosmias to I-pyrroline - the smell of sperm and trimethylamine - the smell of menstrual secretions and women sweat during menses. Meanwhile, a relatively recent study failed to find a link between specific anosmia to trimethylamine and polymorphism of human TAAR5 receptor, which is activated in vitro by this odorant (Wallrabenstein et al., 2013). Recently, Ferdenzi et al. showed a large interindividual variability of sensitivity to major constituents of human axillary odor 3-hydroxy-3-methylhexanoic acid (HMHA) and (E)-3-methylhex-2-enoic acid (3MHA) within two populations. Prevalence of anosmia was determined as $8 \%$ and $19 \%$ for HMHA in France and Madagascar respectively, and 25\% for 3MHA in France (Ferdenzi et al., 2019). If there is any linkage between specific anosmias to body odor compounds and their involvement into human social communication, still remains to be elucidated.

Genetic influences: Olfactory sensitivity to androstenone (AND) is largely determined by genetic factors. Wysocki and Beauchamp showed that concordance in ability or inability to detect the odor of AND in pairs of monozygous (identical) twins was 100\%, while in pairs of dizygotic (non-identical) twins was only 61\% (Wysocki \& Beauchamp, 1984). The coefficient of correlation between the olfactory thresholds to AND in identical twins was 0.95 , while in non-identical twins 0.22 , which confirms the significance of the genetic factors. Close estimates were obtained in another sample of twins by an independent group of researchers (Gross-Isseroff et al., 1992). Analysis of family pedigrees (67 families from the Philadelphia area, USA) revealed the complex mode of the inheritance of olfactory sensitivity to AND. The researchers suggested explanation of the observed distribution through the possible linkage of the trait to the $X$ chromosome, but this hypothesis did not receive further attention (Wysocki \& Beauchamp, 1991). Another study, performed on an impressive sample of twin pairs (a total of 917 people from 4 countries), estimated the contribution of genetic and environmental factors to the variability of olfactory sensitivity to the AND (Knaapila et al., 2008). The analysis based on the assumption that monozygotic twins have a completely identical set of genes, and dizygotic ones are only half identical, while both types of twin pairs are equally affected by environmental factors. It was found that additive genetic effects explain $28 \%$ of the phenotypic variability in the intensity of the perception of the odor of the AND and $21 \%$ in pleasantness of the smell perception. Highly likely that low estimates of genetic influence were due to the use of an approximate "scratch-and-sniff" test carried out in most cases under uncontrolled conditions. A significant impact of genetic factors was confirmed by the development of several mouse genetic models of specific anosmia (Table 1).

Table 1. Mouse models of specific anosmias.

\begin{tabular}{|c|c|c|c|}
\hline Odorant & $\begin{array}{l}\text { Mouse strains, contrasting in } \\
\text { olfactory sensitivity }\end{array}$ & $\begin{array}{l}\text { Method of determining olfactory } \\
\text { sensitivity }\end{array}$ & Reference \\
\hline \multirow[t]{3}{*}{$\begin{array}{l}\text { Isovaleric } \\
\text { acid }\end{array}$} & AKR/J and C57BI/6J inbred strains & $\begin{array}{l}\text { Odor-conditioned aversion behavioral } \\
\text { approach (LiCl injection) }\end{array}$ & $\begin{array}{l}\text { Wysocki et al., 1977; } \\
\text { Pourtier \& Sicard, } 1990\end{array}$ \\
\hline & & Electro-olfactogram recordings & $\begin{array}{l}\text { Troitskaya et al., 1987; } \\
\text { Wang et al., } 1993\end{array}$ \\
\hline & DBA/2J and $\mathrm{C} 57 \mathrm{BI} / 6 \mathrm{~J}$ inbred strains & $\begin{array}{l}\text { Odor-conditioned aversion behavioral } \\
\text { approach ( } \mathrm{LiCl} \text { injection) }\end{array}$ & Griff \& Reed, 1995 \\
\hline $\begin{array}{l}\text { Geraniol, } \\
\text { phenylethyl } \\
\text { alcohol }\end{array}$ & $\begin{array}{l}\text { Animals with different sensitivity } \\
\text { were selected from outbred Swiss } \\
\text { strain }\end{array}$ & $\begin{array}{l}\text { Odor-conditioned aversion } \\
\text { approach (electroshock) }\end{array}$ & Price, 1977 \\
\hline \multirow[t]{2}{*}{$\begin{array}{l}\text { Androstenon } \\
\text { e }\end{array}$} & CBA/J and NZB/BINJ inbred strains & $\begin{array}{l}\text { Behavioral approach: positive food and } \\
\text { water reward tests, aversive drink } \\
\text { reinforcement }\end{array}$ & $\begin{array}{l}\text { Voznessenskaya et al., } \\
\text { 1995; Voznessenskaya et } \\
\text { al., 1999 }\end{array}$ \\
\hline & & $\begin{array}{l}\text { Electro-olfactogram recordings and } \\
\text { conditioned aversion }\end{array}$ & Wang et al., 1993 \\
\hline
\end{tabular}

Animal model of specific anosmia to androstenone (AND) was developed using two inbred mouse strains CBA/J (CBA) and NZB/BINJ (NZB) having a contrasting olfactory sensitivity to AND. These two mouse strains were selected from more than 20 Jackson laboratories mouse strains in a preliminary screen. CBA mice are more than 2000 times more sensitive to AND than NZB mice (Voznessenskaya et al., 1995). Olfactory thresholds at the behavioral level were determined using three different approaches in these two mouse strains.

The recessive Mendelian mode of the inheritance of specific anosmia to isovaleric acid (IVA) was demonstrated in F1 hybrids from crosses of parental inbred mouse strains with alternate sensitivity to this odor. That was shown at the behavioral level in C57BI/6] x DBA/J cross progeny (Griff \& Reed, 1995) and by electrical olfactogram recordings from olfactory epithelium of C57BI/6 $\times$ AKR offspring (Novikov et al., 2002).

Quantitative trait locus (QTL) analysis is a powerful genetic tool for mapping chromosome regions that determine complex polygenic traits. The loci on mouse chromosomes 4 and 6, Iva1 and Iva2, respectively, were associated with olfactory sensitivity to isovaleric acid, using recombinant mouse strains obtained by crossing insensitive C57B//6J mice and sensitive DBA/J (Griff \& Reed, 1995). The observed segregation of androstenone (AND) olfactory threshold phenotypes in F2 hybrids derived from NZB $\times$ CBA cross allowed us to perform chromosomal linkage analysis. An association analysis revealed suggestive linkages for AND sensitivity on mouse chromosomes 2, 12 and 17, and a significant male sex-specific linkage on 
chromosome 10 (Klyuchnikova et al., 2015). Intriguingly, the linkage on chromosome 10 overlaps with intermale aggression trait linkage (Klyuchnikova \& Voznessenskaya, 2011).

New methods of functional expression of olfactory receptor (OR) genes in cell culture allowed to study ligand spectrum of individual human ORs (Abaffy et al. 2006; Zhuang \& Matsunami, 2007). Using an outstanding combination of molecular biological and psychophysical methods, Keller and colleagues detected human olfactory receptor OR7D4 as a receptor of closely related steroids androstenone (AND) and androstadienone (Keller et al., 2007). OR7D4, expressed in Hana3A cells, gave the most specific response to AND and androstadienone among the other remaining 335 cloned ORs. The most frequently found in the population allelic variant of OR7D4 (RT) responded selectively to stimulation with both steroids, while the other allelic variant (WM), differing only in two amino acid substitutions, was not activated by any of the 66 tested odorants. Keller et al. (2007) showed that individuals heterozygous for the gene OR7D4 (RT/WM) are more sensitive to AND than individuals homozygous for the WM allele (WM/WM). Subjects with the RT/WM genotype more often identified the smell of AND as unpleasant than those with the WM/WM genotype. The percentage of variability in the population, which is explained by the OR7D4 genotype, assessed using non-parametric regression analysis, was $19 \%$ for the intensity of perception of smell and 39\% for its pleasantness. Thus, the OR7D4 genotype was identified as a significant genetic factor influencing sensitivity to AND. It is particularly important that this work was the first experimental confirmation of the link between genetic variants of OR and the manifestation of specific anosmia. OR7D4 genetic factor was later confirmed in a large-scale study (over 1800 subjects) by Knaapila et al. (2012). In a research conducted by Lunde et al. (2012) subjects with two copies of the RT allele rated the AND-containing meat as less favorable than subjects with the WM allele. Thus, genetic variation in OR7D4 may affect food preferences. Meanwhile, in a recent study of Hornung et al. (2018) homozygous carriers of RT allele did not rate the related steroid androstedienone as more intense and unpleasant than heterozygous carriers nor did sensitivity towards the odorant differ between these groups ( $n=72)$.

In parallel to the described above, Menashe and colleagues studied genetic determinants of sensitivity to isovaleric acid (Menashe et al., 2007). However, here the attention of researchers was drawn not to the known genes of functional olfactory receptors, but to a selected group of segregating pseudogenes (authors described 66 such genes). Single nucleotide mutations (SNPs) in those OR pseudogenes lead to a transition to a functional state. Researchers found a statistically significant association between the presence of a nonsense mutation in the OR11H7P coding region and the detection thresholds of isovaleric acid. This mathematically predicted relationship has been confirmed by the functional expression of this receptor in Xenopus laevis oocytes (Menashe et al., 2007).

Summarizing the latest research on the search for genetic loci and olfactory receptor genes that control sensitivity to androstenone (AND) and isovaleric acid (IVA), we note that some inconsistencies between human and animal models still are not resolved. For instance, it is known that genes of mouse olfactory receptors located in clusters on all chromosomes except 12 and $Y$ (Zhang \& Firestein 2002). Meanwhile, among two QTLs for olfactory sensitivity to IVA on mouse chromosomes 4 and 6 , only one on chromosome 4 contains genes of olfactory receptors (Griff \& Reed, 1995). However, in humans, the cluster of orthologous genes was generally lost in the process of evolution (Aloni et al., 2006). Vice versa, mouse gene ortholog of human olfactory receptor segregating pseudogene OR11H7P (Menashe et al., 2007) does not map to mouse chromosomes 4 or 6. Our research in mouse model of specific anosmia to AND (details are provided above) showed that several genetic loci may be involved (Klyuchnikova et al., 2015). We also investigated genes located within the QTL intervals to find candidates that are either olfactory receptor genes or are implicated in genetic control of olfactory sensitivity to AND in humans (Keller et al., 2007; Knaapila et al., 2012). But, like in case with IVA anosmia, we could not show association of OR7D4 mouse gene ortholog with mouse olfactory sensitivity to AND. However, locus on mouse chromosome 12 has a conserved synteny with a human genome region associated with AND sensitivity in large scale study (Knaapila et al., 2012). Intriguingly, this locus does not contain olfactory receptor genes. Nevertheless, we cannot argue the fact that human individual variation in olfactory sensitivity is strongly associated with OR genes polymorphisms.

\section{Sex-related, age-related and environmental influences}

It is well known that general olfactory sensitivity gradually declines in elderly people (i.e. Doty \& Kamath, 2014); women often show better olfactory abilities than men. However, for odorants with documented specific anosmia age- and sex-related patterns may be more complicated.

Research performed for several age and sex defined groups, revealed a significant decrease in androstenone (AND) sensitivity with age, especially in men. Most children at the age of 3 likely detect AND (Schmidt \& Beauchamp, 1988). Meanwhile, the occurrence of specific anosmia to AND in males at the age of 15-20 years is three times higher than that at the age of 9-14 years (Dorries et al., 1989). These results were confirmed in the large population study performed with assistance of National Geographic magazine (Wysocki \& Gilbert, 1989). Moreover, even in males who remained sensitive to AND after sexual maturation, olfactory detection thresholds to this substance increased. In females, another trend was observed, as far as a tendency for decrease in sensitivity was less profound. However, women who were initially sensitive to AND became even more sensitive over time, though their sensitivity to control odor of pyridine did not change (Wysocki \& Beauchamp, 1991). The reasons for such specific decrease in olfactory sensitivity in men by the time of sexual maturation and the observed sexual dimorphism are not clear. Among the suggested explanations are changes in olfactory system caused by elevation of sexual hormones, or adaptation to the odor as a result of increase in self-secretion of odorous steroids. An independent group of researchers confirmed the same age and sex dependent pattern for olfactory sensitivity changes towards closely related steroid androstadienone (Hummel et al., 2005). Later reports propose that the observation also extends towards other malodors since a decline in olfactory sensitivity in boys during puberty was also noted in relation to some other, unrelated to AND, unpleasant odors (Chopra et al., 2008). 
Some experimental data (Lübke \& Pause, 2014) suggest a link between sex-hormone levels and perception of androstenone (AND). In men, higher testosterone levels were associated with lower olfactory sensitivity to AND. In women, higher estradiol levels were related to rating AND as more unpleasant.

To the best of our knowledge, age dynamics of olfactory sensitivity to isovaleric acid (IVA) were never studied in humans. Though related data were obtained in rodents: sensitivity of mice to the odor of IVA reaches maximum in immature animals, both in males and females, and gradually decreases with age. A significant decrease in sensitivity to IVA was observed in male mice by the fourth month of development compared to one-month old animals (Boryakova et al., 2007; Melnik et al., 2009). Induced olfactory sensitivity in humans was demonstrated for the first time using androstenone molecule (AND). Wysocki and colleagues showed that half of the test subjects with specific anosmia to AND after daily smelling (three times a day for 3 minutes) became sensitive to the odor in one to three weeks after the start of exposure. At the same time, the sensitivity to the control odorants of pyridine and amyl acetate did not change during the experiment (Wysocki et al., 1989). In initially sensitive to androstenone individuals the thresholds to this substance were also lowered after repeated exposures (Wang et al., 2004). This effect has also been demonstrated in a mouse model of CBA/J (CBA) and NZB/B1NJ (NZB) inbred strains. After 3 weeks of exposure to AND for 16 hours per day of 7 weeks old mice, the sensitivity to AND in CBA mice increased 200-400 times, in NZB mice sensitivity increased 64-128 times. Similar exposures of CBA mice at the age of 14-28 days (critical period for odor sensitization) resulted in 600-fold increase in sensitivity to androstenone by the age of 7-9 weeks compared to control group (Voznessenskaya et al., 1995; Voznessenskaya et al., 1999a). Notably, the induction of olfactory sensitivity in rodents also was demonstrated for wide array of biologically relevant odor mixtures indicating the generality of the described phenomenon, at least, in rodents (Voznessenskaya et al., 1995; Sokolov et al., 1996). The existence of the critical period for maximal sensitization to particular odors during early postnatal development was confirmed in laboratory mice and rats (Voznessenskaya et al., 1995; Sokolov et al., 1996; Sokolov \& Voznessenskaya, 1997; Voznessenskaya et al. 2016a). The elevated sensitivity to odorants has a long lasting nature: olfactory thresholds to target odors remained significantly lowered, at least for 8 months after completion of the exposure (Voznessenskaya et al., 1999b). The phenomenon of induced sensitivity to a range of odorants (benzaldehyde, citralva) in women of reproductive age has been confirmed by other groups of researchers (Dalton et al., 2002). Positive influence of olfactory training of specific anosmics to the target odors was demonstrated by Croy et al. (2015).

In experiments with elecrophysiological recordings from olfactory epithelium of C57BI/6J mice (anosmic to isovaleric acid), the response increased after intermittent exposure to this odor (Wang et al., 1993). A number of studies on mouse olfactory epithelium preparations (Troitskaya et al., 1987; Wang et al., 1993) as well as studies in humans (Wang et al., 2004; Lapid et al., 2009) demonstrated that the amplitude of the response correlated with the sensitivity to particular odor.

Two basic mechanisms may underlie the induced sensitivity to odors: peripheral and central. For the first suggested mechanism, it is assumed that the interaction, for example, of androstenone (AND) with olfactory sensory neurons leads to an increase in the number of specific or nonspecific receptors for this odorant. For another mechanism, it is suggested that the induction occurs due to central influences. Data obtained from electrophysiological recordings from the olfactory epithelium in laboratory animals as well as human studies point to the peripheral mechanism of plasticity. The amplitude of the electrophysiological response increased after two weeks of exposure to AND in the initially insensitive to the compound NZB mice (Wang et al., 1993). The similar effect was observed after AND exposures in human test subjects initially low sensitive to AND (Wang et al., 2004). Interestingly, such an increase in electrophysiological response was not observed in highly sensitive to AND CBA mice, while at the behavioral level a significant increase in sensitivity to AND was recorded (Voznessenskaya et al., 1995). Intermittent exposures to AND for 2 weeks also caused a significant increase in number of Fospositive cells in vomeronasal receptor epithelium in inbred mice (Voznessenskaya et al., 2010). Biochemical studies showed a correlation between sensitivity to AND and activity of membrane alkaline phosphatase in vomeronasal epithelium of laboratory mice and rats (Chukhray et al.,1992, 1995). One-week exposure to AND was sufficient to produce an irreversible conformational isomerization of an immobilized (membrane) form of alkaline phosphatase from the olfactory and vomeronasal epithelium in CBA mice (Chukhray et al., 1997a,b; Poltorak et al., 1997; Voznessenskaya et al., 1999a). Another evidence for the peripheral mechanism of induced sensitivity comes from the study of Yee and Wysocki, in which CBA mice previously exposed to AND underwent bilateral olfactory nerve transaction. After recovery mice still showed increased sensitivity to the compound (1), CBA mice acquired increased sensitivity being exposed to AND after operation (2) (Yee \& Wysocki, 2001). Nevertheless, the available experimental data on the relationship between shifts in sensitivity at the level of behavior and changes at the level of the receptor olfactory epithelium do not exclude the involvement of central components of olfactory system. For instance, explaining their results, Yee and Wysocki discuss possible centrifugal influences as the fibers grow with uneven regeneration of the olfactory nerve (Yee \&Wysocki, 2001). Anyway, the odorants themselves may enter the body, for example, through the lungs and then spread through the blood stream to the other tissues producing pharmacological effect, or some hormonal factors may play a role in the induction of sensitivity. But relatively small number of studies demonstrated the involvement of central components of olfactory system in sensitization processes. In one study, specific anosmics to AND were subjected to repeated exposures to this odorant through one nostril. Another nostril was "turned off" as humid air was forced through it to avoid the retronasal flow of the odorant. As a result, the thresholds to AND decreased equally for both nostrils (Mainland et al., 2002). The data obtained using a mouse model, also suggest an involvement of central mechanisms in sensitization processes. Induction of sensitivity to AND in CBA mice was followed by a significant increase in number of Fos-positive cells in the main and accessory olfactory bulbs (Voznessenskaya \& Klyuchnikova, 2009) indicating the involvement of central pathways. Sensitization of C57BL/6J mice to cat specific molecule L- 
felinine (Voznessenskaya et al., 2016b) also correlated with significant increase of Fos-positive cells in accessory olfactory bulb which suggests that both discussed mechanisms of plasticity occur.

The possibility of modifying the olfactory sensitivity of a species to various kinds of odorants, depending on the surrounding odor environment and the previous history of olfactory contacts, expands its adaptive capabilities. Physiological changes in olfactory abilities could give advantages in searching for a potential mate, distant food sources, or identifying potential danger cues. Ultimately, olfactory plasticity determines the adaptability of the species to the environment.

\section{Conclusion}

Specific anosmia serves an excellent model for diverse studies of individual variability in olfactory sensitivity for humans and animals. Up to date, specific anosmia to sex boar pheromone androstenone (AND) received the most detailed scientific description. Variability in sensitivity to AND is influenced by genotype, age, gender and individual olfactory experience. However, more specific genetic and physiological mechanisms underlying these influences have not yet been largely revealed. Apparently, individual differences in sensitivity to AND and closely related steroid androstadienone, are associated with variations in the olfactory receptor genes, including the alleles of the OR7D4 gene. However, large data pile from extensive human and animal studies suggests that other undetermined genetic factors are also involved. The induction of olfactory sensitivity to AND as well as to other biologically relevant odors is a general phenomenon that may reflect the plasticity of information processing in the brain and provide instances of stimulus-controlled gene expression in the periphery. The possibility to modify olfactory sensitivity to biologically relevant odors facilitates the adaptability of the species to certain environment. Mechanisms that underlie the phenomenon still remain to be elucidated. Potentially, solving this problem will give insight into fundamental basis of chemical communication.

\section{Acknowledgement}

Supported by IEE Project 0109-2018-0079.

\section{References}

Abaffy, T., Matsunami, H., \& Luetje, C. W. (2006). Functional analysis of a mammalian odorant receptor subfamily. J Neurochem, 97(5), 1506-1518. doi:10.1111/j.1471-4159.2006.03859.x

Amoore, J. E. (1952). The stereochemical specificities of human olfactory receptors. Perfum Essent Oil Rec., 33, 321-323.

Amoore, J. E. (1967). Specific anosmia: a clue to the olfactory code. Nature, 214(5093), 1095-1098. doi:10.1038/2141095a0

Amoore, J. E., Pelosi, P., \& Forrester, L. J. (1977). Specific anosmias to 5a-androst-16-en-3-one and w-pentadecalactone: the urinous and musky primary odors. Chemical Senses and Flavor, 2(4), 401-425. doi:10.1093/chemse/2.4.401.

Amoore, J. E. (1979). Directions for preparing aqueous solutions of primary odorants to diagnose eight types of specific anosmia. Chem Senses and Flavor, 4, 153-161. doi:10.1093/chemse/4.2.153.

Boesveldt, S., Postma, E. M., Boak, D., Welge-Luessen, A., Schopf, V., Mainland, J. D., Duffy, V. B. (2017). Anosmia-A Clinical Review. Chem Senses, 42(7), 513-523. doi:10.1093/chemse/bjx025.

Boryakova, E. E., Gladysheva, O. S., Krylov, V. N. (2007). Age dynamics of laboratory mice and rats females olfactory sensitivity to isovaleric acid. Sensornye sistemy, 21(4), 341-346. (in Russian)

Boyle, J. A., Lundstrom, J. N., Knecht, M., Jones-Gotman, M., Schaal, B., \& Hummel, T. (2006). On the trigeminal percept of androstenone and its implications on the rate of specific anosmia. J Neurobiol, 66(13), 1501-1510. doi:10.1002/neu.20294

Bremner, E. A., Mainland, J. D., Khan, R. M., \& Sobel, N. (2003). The prevalence of androstenone anosmia. Chem Senses, 28(5), 423-432. doi:10.1093/chemse/28.5.423

Buck, L., \& Axel, R. (1991). A novel multigene family may encode odorant receptors: a molecular basis for odor recognition. Cell, 65(1), 175-187. doi:10.1016/0962-8924(91)90063-f

Bushdid, C., Magnasco, M. O., Vosshall, L. B., \& Keller, A. (2014). Humans can discriminate more than 1 trillion olfactory stimuli. Science, 343(6177), 1370-1372. doi:10.1126/science.1249168

Chopra, A., Baur, A., \& Hummel, T. (2008). Thresholds and chemosensory event-related potentials to malodors before, during, and after puberty: differences related to sex and age. Neuroimage, 40(3), 1257-1263. doi:10.1016/j.neuroimage.2008.01.015

Chukhrai, E.S., Atyaksheva, L. F., Poltorak, O. M., Voznesenskaya, V. V., Wysocki, C. J. (1997a). Modeling of the primary reception of odorants on natural transport proteins. Zhurnal Fizicheskoi Khimii, 71(2), 347-350.

Chukhrai, E. S., Poltorak, O. M., Atyaksheva, L. F., Veselova, M.N., Voznessenskaya, V. V., Wysocki, C. J. (1995). Soluable alkaline phosphatase as the transport protein of hydrophobic odorants. Zhurnal Fizicheskoi Khimii, 69(2), 336-339

Chukhrai, E. S., Poltorak, O. M., Atyaksheva, L. F., Voznessenskaya, V. V., Wysocki, C. J. (1997b). The influence of androstenone on the properties of immobilized alkali phosphatase in natural membranes responsible for reception of odorants. Zhurnal Fizicheskoi Khimii, 71(7), 1315-1319.

Chukhray, E. S., Veselova, M.N., Poltorak, O. M., Voznessenskaya, V. V., Zinkevich, E.P., Wysocki, C. J. (1992b). Phosphatase activity of rat olfactory and vomeronasal epithelial tissue. In Schulte, R. L., Doty, D., Muller-Schwarze (Eds.). Chemical Signals in Vertebrates 6 (pp. 43-47). Plenum Press. doi: 10.1007/978-1-4757-9655-1_8

Cowley, J. J., Johnson, A. L., \& Brooksbank, B. W. (1977). The effect of two odorous compounds on performance in an assessment-of-people test. Psychoneuroendocrinology, 2(2), 159-172. doi:10.1016/0306-4530(77)90021-x 
Croy, I., Olgun, S., Mueller, L., Schmidt, A., Muench, M., Hummel, C., Hummel, T. (2015). Peripheral adaptive filtering in human olfaction? Three studies on prevalence and effects of olfactory training in specific anosmia in more than 1600 participants. Cortex, 73, 180-187. doi:10.1016/j.cortex.2015.08.018

Dalton, P., Doolittle, N., \& Breslin, P. A. (2002). Gender-specific induction of enhanced sensitivity to odors. Nat Neurosci, 5(3), 199-200. doi:10.1038/nn803

Dorries, K. M., Schmidt, H. J., Beauchamp, G. K., \& Wysocki, C. J. (1989). Changes in sensitivity to the odor of androstenone during adolescence. Dev Psychobiol, 22(5), 423-435. doi:10.1002/dev.420220502

Doty, R. L., \& Kamath, V. (2014). The influences of age on olfaction: a review. Applied Olfactory Cognition, 5, 213-232. doi:10.3389/fpsyg.2014.00020

Ferdenzi, C., Razafindrazaka, H., Baldovini, N., Poupon, D., Pierron, D., \& Bensafi, M. (2019). Influence of gender and culture on the perception of acidic compounds of human body odor. Physiol Behav, 112561. doi: 10.1016/j.physbeh.2019.112561

Filsinger, E. E., Braun, J. J., Monte, W. C., \& Linder, D. E. (1984). Human (Homo sapiens) responses to the pig (Sus scrofa) sex pheromone 5 alpha-androst-16-en-3-one. J Comp Psychol, 98(2), 219-222. doi:10.1037/0735-7036.98.2.219

Firestein, S., Picco, C., \& Menini, A. (1993). The relation between stimulus and response in olfactory receptor cells of the tiger salamander. J Physiol, 468, 1-10. doi:10.1113/jphysiol.1993.sp019756

Gerkin, R. C., \& Castro, J. B. (2015). The number of olfactory stimuli that humans can discriminate is still unknown. Elife, 4, e08127. doi:10.7554/eLife.08127

Gilbert, A. N., Wysocki C. J. (1987). The smell survey results. National Geographic, 172, 514-522.

Glusman, G., Yanai, I., Rubin, I., \& Lancet, D. (2001). The complete human olfactory subgenome. Genome Res, 11(5), 685-702. doi:10.1101/gr.171001

Gower, D. B., \& Ruparelia, B. A. (1993). Olfaction in humans with special reference to odorous 16-androstenes: their occurrence, perception and possible social, psychological and sexual impact. J Endocrinol, 137(2), 167-187. doi:10.1677/joe.0.1370167

Griff, I. C., \& Reed, R. R. (1995). The genetic basis for specific anosmia to isovaleric acid in the mouse. Cell, 83(3), 407-414. doi:10.1016/0092-8674(95)90118-3

Guillot, M. (1948). Anosmies partielles et odeurs fondamentales. CR Hebd Acad Sci, 226, 1307-1309.

Hoehn, R. D., Nichols, D. E., Neven, H., \& Kais, S. (2018). Status of the Vibrational Theory of Olfaction. Frontiers in Physics, 6(25). doi:10.3389/fphy.2018.00025

Hornung, J., Noack, H., Thomas, M., Farger, G., Nieratschker, V., Freiherr, J., \& Derntl, B. (2018). Bayesian informed evidence against modulation of androstadienone-effects by genotypic receptor variants and participant sex: A study assessing Stroop interference control, mood and olfaction. Horm Behav, 98, 45-54.doi:10.1016/j.yhbeh.2017.12.003.

Hummel, T., Krone, F., Lundstrom, J. N., \& Bartsch, O. (2005). Androstadienone odor thresholds in adolescents. Horm Behav, 47(3), 306-310. doi:10.1016/j.yhbeh.2004.10.007

Ingersoll, D. W., \& Launay, J. (1986). Murine aggression induced by a boar chemosignal: a stimulus presentation dependency. Physiol Behav, 36(2), 263-269. doi:10.1016/0031-9384(86)90014-4

Kajiya, K., Inaki, K., Tanaka, M., Haga, T., Kataoka, H., \& Touhara, K. (2001). Molecular bases of odor discrimination: Reconstitution of olfactory receptors that recognize overlapping sets of odorants. J Neurosci, 21(16), 6018-6025. doi:10.1523/jneurosci.21-16-06018.2001

Katada, S., Hirokawa, T., Oka, Y., Suwa, M., \& Touhara, K. (2005). Structural basis for a broad but selective ligand spectrum of a mouse olfactory receptor: mapping the odorant-binding site. J Neurosci, 25(7), 1806-1815. doi:10.1523/jneurosci.4723-04.2005 Keller, A., \& Vosshall, L. B. (2016). Olfactory perception of chemically diverse molecules. BMC Neurosci, 17(1), 55. doi:10.1186/s12868-016-0287-2

Keller, A., Zhuang, H., Chi, Q., Vosshall, L. B., \& Matsunami, H. (2007). Genetic variation in a human odorant receptor alters odour perception. Nature, 449(7161), 468-472. doi.org/10.1038/nature06162

Klyuchnikova, M. A., Bosak, N. P., Lin, C., Bachmanov, A. A., Wysocki, C. J., Voznessenskaya, V. V. (2015). Genetic control of specific anosmia to androstenone in a mouse model. Chem Sens. 40(3), 277-278.

Klyuchnikova, M. A., Voznesenskaya, V. V. (2011). Genetic regulation of intermale aggression in the house mouse. Doklady Biol Sci. 436, 26-28. doi:10.1134/s0012496611010029

Knaapila, A., Tuorila, H., Silventoinen, K., Wright, M. J., Kyvik, K. O., Cherkas, L. F., Perola, M. (2008). Genetic and Environmental Contributions to Perceived Intensity and Pleasantness of Androstenone Odor: An International Twin Study. Chemosensory Perception, 1(1), 34-42. doi:10.1007/s12078-007-9005-x

Knaapila, A., Zhu, G., Medland, S. E., Wysocki, C. J., Montgomery, G. W., Martin, N. G., Reed, D. R. (2012). A genome-wide study on the perception of the odorants androstenone and galaxolide. Chem Senses, 37(6), 541-552. doi:10.1093/chemse/bjs008

Krautwurst, D., Yau, K. W., \& Reed, R. R. (1998). Identification of ligands for olfactory receptors by functional expression of a receptor library. Cell, 95(7), 917-926. doi:10.1016/s0092-8674(00)81716-x

Labows, J., \& Wysocki, C. (1984). Individual differences in odor perception. Perfumer \& flavorist 9(1), 21-26.

Lapid, H., Seo, H. S., Schuster, B., Schneidman, E., Roth, Y., Harel, D., Hummel, T. (2009). Odorant concentration dependence in electroolfactograms recorded from the human olfactory epithelium. J Neurophysiol, 102(4), 2121-2130. doi:10.1152/jn.91321.2008

Liberles, S. D., \& Buck, L. B. (2006). A second class of chemosensory receptors in the olfactory epithelium. Nature, 442(7103), 645-650. doi:10.1038/nature05066 
Liberles, S. D. (2015). Trace amine-associated receptors: ligands, neural circuits, and behaviors. Current opinion in neurobiology, 34, 1-7. doi:10.1016/j.conb.2015.01.001

Lubke, K. T., \& Pause, B. M. (2014). Sex-hormone dependent perception of androstenone suggests its involvement in communicating competition and aggression. Physiol Behav, 123, 136-141. doi: 10.1016/j.physbeh.2013.10.016.

Lunde, K., Egelandsdal, B., Skuterud, E., Mainland, J. D., Lea, T., Hersleth, M., \& Matsunami, H. (2012). Genetic variation of an odorant receptor OR7D4 and sensory perception of cooked meat containing androstenone. PLoS ONE, 7(5), e35259. doi:10.1371/journal.pone.0035259.

Mainland, J. D., Bremner, E. A., Young, N., Johnson, B. N., Khan, R. M., Bensafi, M., \& Sobel, N. (2002). Olfactory plasticity: one nostril knows what the other learns. Nature, 419(6909), 802. doi:10.1038/419802a

Malnic, B., Hirono, J., Sato, T., \& Buck, L. B. (1999). Combinatorial receptor codes for odors. Cell, 96(5), 713-723. doi:10.1016/s0092-8674(00)80581-4

McGann, J. P. (2017). Poor human olfaction is a 19th-century myth. Science, 356(6338). doi:10.1126/science.aam7263

Melnik, S. A., Gladysheva, O. S., Krylov, V. N. (2009). Age-variation of olfactory sensitivity to isovaleric acid in male mice. Sensornye systemi. 23(2), 151-155. (in Russian)

Menashe, I., Abaffy, T., Hasin, Y., Goshen, S., Yahalom, V., Luetje, C. W., \& Lancet, D. (2007). Genetic elucidation of human hyperosmia to isovaleric acid. PLoS Biol, 5(11), e284. doi:10.1371/journal.pbio.0050284

Menashe, I., Man, O., Lancet, D., \& Gilad, Y. (2003). Different noses for different people. Nat Genet, 34(2), 143-144. doi:10.1038/ng1160

Michael, R. P., Bonsall, R. W., \& Kutner, M. (1975). Volatile fatty acids, "copulins", in human vaginal secretions. Psychoneuroendocrinology, 1(2), 153-163. doi:10.1016/0306-4530(75)90007-4

Michael, R. P., Keverne, E. B., \& Bonsall, R. W. (1971). Pheromones: isolation of male sex attractants from a female primate. Science, 172(986), 964-966. doi:10.1126/science.172.3986.964

Mombaerts, P. (2004). Odorant receptor gene choice in olfactory sensory neurons: the one receptor-one neuron hypothesis revisited. Curr Opin Neurobiol, 14(1), 31-36. doi:10.1016/j.conb.2004.01.014

Moncrieff, R. W. (1949). What is odor? A new theory. Am. Perfum. Essent. Oil Rev., 54, 453-454.

Muller-Schwarze, D., Muller-Schwarze, C., Singer, A. G., \& Silverstein, R. M. (1974). Mammalian pheromone: Identification of active component in the subauricular scent of the male pronghorn. Science, 183, 860-862. doi:10.1126/science.183.4127.860

Novikov, S. N. (1988). Pheromones and reproduction in mammals: physiological aspects. Leningrad: Nauka. (in Russian)

Novikov, S. N., Troitskaya, V. T., Gladysheva, O. S., \& Churakov, G. A. (2002). Specific anosmia to isovaleric acid in laboratory C57BL/6 mice: recessive inheritance. Dokl Biol Sci, 387, 505-507. doi.org/10.1023/a:1021768919888

Pause, B. M. (2004). Are androgen steroids acting as pheromones in humans? Physiol Behav, 83(1), 21-29. doi:10.1016/j.physbeh.2004.07.019

Poltorak, O. M., Chukhrai, E. S., Atyaksheva, L. F., Veselova, M. N., Voznessenskaya, V. V. (1997). Properties of immobilized alkaline phosphatase in native membranes at reception of odorants. Zhurnal Fizicheskoi Khimii, 71(8), $1505-1509$.

Pourtier, L., \& Sicard, G. (1990). Comparison of the sensitivity of C57BL/6J and AKR/J mice to airborne molecules of isovaleric acid and amyl acetate. Behav Genet, 20(4), 499-509. doi:10.1007/bf01067716

Price, S. (1977). Specific anosmia to geraniol in mice. Neurosci Lett, 4(1), 49-50. doi:10.1016/0304-3940(77)90123-9

Reed, H. C., Melrose, D. R., \& Patterson, R. L. (1974). Androgen steroids as an aid to the detection of oestrus in pig artificial insemination. Br Vet J, 130(1), 61-67. doi:10.1016/s0007-1935(17)37337-2

Sato, T., Hirono, J., Tonoike, M., \& Takebayashi, M. (1994). Tuning specificities to aliphatic odorants in mouse olfactory receptor neurons and their local distribution. J Neurophysiol, 72(6), 2980-2989. doi:10.1152/jn.1994.72.6.2980

Schmidt, H. J., \& Beauchamp, G. K. (1988). Adult-like odor preferences and aversions in three-year-old children. Child Dev, (59), 1136-1143. doi:10.2307/1130280

Sicard, G., \& Holley, A. (1984). Receptor cell responses to odorants: similarities and differences among odorants. Brain Res, 292(2), 283-296. doi:10.1016/0006-8993(84)90764-9

Sokolov, V. E., Voznesenskaia, V. V., Parfenova, V. M., \& Wysocki, C. J. (1996). Induced sensitivity to odorants: a new phenomenon. Dokl Akad Nauk, 347(6), 843-846. (in Russian)

Sokolov, V. E., Voznessenskaya, V. V. (1997). A role of early olfactory experience in the individual recognition in gray rats (Rattus norvegicus). Dokl Akad Nauk, 355(1), 140-142. (in Russian)

Touhara, K. (2002). Odor discrimination by G protein-coupled olfactory receptors. Microsc Res Tech, 58(3), 135-141. doi:10.1002/jemt.10131

Touhara, K. (2008). Structure, expression, function of olfactory receptors. In Firestein, S. \& Beauchamp G. K. (Eds.). The senses: A comprehensive reference. V.4. Olfaction and taste (pp. 527-544). Amsterdam, Boston: Elsevier. doi:10.1016/b978012370880-9.00108-0

Troitskaia, V. T., Gladysheva, O. S., Novikov, S. N. (1987). Specific anosmia to isovaleric acid in the peripheral portion of the olfactory analyzer of the laboratory mouse. Neirofiziologiia, 19(1), 133-135. (in Russian)

Voznessenskaya, V. V., Parfyonova, V. M., Wysocki, C. J. (1995). Induced olfactory sensitivity in rodents: A general phenomenon. Adv Biosci, 93, 399-406.

Voznessenskaya, V. V., Wysocki, C. J., Chukhrai, E. S., Poltorack, O. M., Atyaksheva, L. F. (1999a). Long-lasting Effects of Chemical Exposures in Mice. In Johnston, R. E., Müller-Schwarze, D. and Sorensen, P. W (Eds.). Advances in Chemical Signals in Vertebrates (pp. 563-571). NewYork: Kluwer. doi:10.1007/978-1-4615-4733-4_50 
Voznessenskaya, V. V., Wysocki, C. J., Chukhrai, E. S., Poltorack, O. M., Atyaksheva, L. F. (1999b). Is there a time during neonatal development for maximal imprinting for odor? In Johnston, R. E., Müller-Schwarze, D. and Sorensen, P. W (Eds.). Advances in Chemical Signals in Vertebrates (pp. 617-622). NewYork: Kluwer. doi:10.1007/978-1-4615-4733-4_56

Voznessenskaya, V. V., \& Klyuchnikova, M. A. (2009). Induced sensitivity to androstenone: the role for main olfactory system and vomeronasal organ. Chemical Senses, 34(3), E31-32.

Voznessenskaya, V. V., Klyuchnikova, M. A., \& Wysocki, C. J. (2010). Roles of the main olfactory and vomeronasal systems in the detection of androstenone in inbred strains of mice. Current Zoology, 56(6), 813-818.

Voznessenskaya, V. V., Kvasha, I. G., Klinov, A. B., Laktionova, T. K. (2016a). Responses to domestic cat chemical signals in the house mouse are modulated by early olfactory experience. In Schulte, B. A., Goodwin, T. E., Ferkin, M. H. (Eds.). Chemical Signals in Vertebrates 13 (pp. 401-411). Springer. doi:10.1007/978-3-319-22026-0_27

Voznessenskaya, V. V., Kvasha, I. G., Laktionova, T. K., Klyuchnikova, M. A. (2016b). Increased sensitivity to I-felinine in mice correlated with elevated Fos-immunoreactivity in the accessory olfactory bulb. Chemical Senses, 41(7), E89-E90.

Voznessenskaya, V. V., \& Klyuchnikova, M. A. (2017). Individual variability of human olfactory sensitivity to volatile steroids: Environmental and genetic factors. Dokl Biol Sci, 473(1), 77-79. doi:10.1134/s0012496617020144

Wallrabenstein, I., Kuklan, J., Weber, L., Zborala, S., Werner, M., Altmüller, J., Hummel, T. (2013). Human trace amine-associated receptor TAAR5 can be activated by trimethylamine. PLoS ONE, 8(2), e54950. doi:10.1371/journal.pone.0054950

Wang, H. W., Wysocki, C. J., \& Gold, G. H. (1993). Induction of olfactory receptor sensitivity in mice. Science, 260(5110), 9981000. doi:10.1007/978-4-431-68355-1_93

Wang, L., Chen, L., \& Jacob, T. (2004). Evidence for peripheral plasticity in human odour response. J Physiol, 554(Pt 1), 236-244. doi:10.1113/jphysiol.2003.054726

Wyart, C., Webster, W. W., Chen, J. H., Wilson, S. R., McClary, A., Khan, R. M., \& Sobel, N. (2007). Smelling a single component of male sweat alters levels of cortisol in women. J of Neurosci, 27(6), 1261-1265.

Wyatt, T. D. (2015). The search for human pheromones: the lost decades and the necessity of returning to first principles. Proc Biol Sci, 282(1804), 20142994. doi:10.1098/rspb.2014.2994

Wysocki, C. J., \& Beauchamp, G. K. (1984). Ability to smell androstenone is genetically determined. Proc Natl Acad Sci U S A, 81(15), 4899-4902. doi:10.1073/pnas.81.15.4899

Wysocki, C. J., \& Beauchamp, G. K. (1991). Individual differences in olfaction. In Wysocki, C. J. \& Kare, M. R. (Eds.) Genetics of Perception and Communications (pp. 353-373). New York: Dekker.

Wysocki, C. J., Dorries, K. M., \& Beauchamp, G. K. (1989). Ability to perceive androstenone can be acquired by ostensibly anosmic people. Proc Natl Acad Sci U S A, 86(20), 7976-7978. doi:10.1073/pnas.86.20.7976

Wysocki, C. J., Whitney, G., \& Tucker, D. (1977). Specific anosmia in the laboratory mouse. Behav Genet, 7(2), 171-188. doi:10.1007/bf01066005

Yee, K. K., \& Wysocki, C. J. (2001). Odorant exposure increases olfactory sensitivity: olfactory epithelium is implicated. Physiol Behav, 72(5), 705-711. doi:10.1016/s0031-9384(01)00428-0

Yeshurun, Y., Sobel, N. (2010). An odor is not worth a thousand words: from multidimensional odors to unidimensional odor objects. Annu Rev Psychol, 61, 219-41. doi:10.1146/annurev.psych.60.110707.163639

Young, J. M., \& Trask, B. J. (2002). The sense of smell: genomics of vertebrate odorant receptors. Hum Mol Genet, 11(10), 11531160. doi:10.1093/hmg/11.10.1153

Zhang, X., \& Firestein, S. (2002). The olfactory receptor gene superfamily of the mouse. Nat Neurosci, 5(2), 124-133. doi:10.1038/nn800

Zhao, H., Ivic, L., Otaki, J. M., Hashimoto, M., Mikoshiba, K., \& Firestein, S. (1998). Functional expression of a mammalian odorant receptor. Science, 279(5348), 237-242. doi:10.1126/science.279.5348.237

Zhuang, H., \& Matsunami, H. (2007). Synergism of accessory factors in functional expression of mammalian odorant receptors. J Biol Chem, 282(20), 15284-15293. doi:10.1074/jbc.m700386200

Zozulya, S., Echeverri, F., \& Nguyen, T. (2001). The human olfactory receptor repertoire. Genome Biol, 2(6), RESEARCH0018.

Citation: Klyuchnikova, M.A., Voznessenskaya, V.V. (2019). Specific anosmia in humans and animals: environmental and genetic influences. Ukrainian Journal of Ecology, 9(3), 52-59.

(c) $\mathbf{E Y}$ This work is licensed under a Creative Commons Attribution 4.0. License 